\title{
On rheological, mechanical, thermal, wear and morphological properties of melamine formaldehyde reinforced recycled ABS for sustainable manufacturing
}

\author{
Gulraj Singh ${ }^{1}$, Gurinder Singh Brar ${ }^{1 *}$, and Rupinder Singh ${ }^{2}$ \\ ${ }^{1}$ Department of Mechanical Engineering, National Institute of Technology, Uttarakhand, Srinagar (Garhwal), Uttarakhand. 246174 \\ ${ }^{2}$ Department of Mechanical Engineering, NITTTR Chandigarh-160019, India
}

\begin{abstract}
This study outline the procedure of filament fabrication for fused deposition modelling (FDM), based upon rheological, mechanical, thermal, wear and morphological characterization as a case study of acrylonitrile butadiene styrene (ABS) - melamine formaldehyde (MF) composite. It has been ascertained that with increase in proportion of MF in ABS, viscosity is improved and melt flow index (MFI) is reduced significantly. As regards to the wear behavior is concerned it has been observed that ABS-MF (12.5 wt.\%) composite has shown minimum weight loss and porosity. For the mechanical properties of the composite, experimental results show increased brittleness of the samples with addition of MF reinforcement. The thermal stability analysis was performed using differential scanning calorimetry (DSC) for virgin ABS and samples having $12.5 \% \mathrm{MF}$ in $\mathrm{ABS}$ and results show the increased heat capacity of the material with increase in MF percentage. Further for sustainability analysis (based upon thermal stability), matrix of ABSMF12.5\% was subjected to three repeated thermal (heating-cooling) cycles and it has been ascertained that no significant loss was noticed in heat capacity of recycled composite matrix. The results are also supported by Fourier transform infrared spectroscopy (FTIR) analysis. Overall the results of the rheological, mechanical, wear, morphological and thermal properties suggested that $12.5 \%$ proportion of MF can be reinforced into selected grade of $\mathrm{ABS}$ thermoplastic for 3D printing as a sustainable solution.
\end{abstract}

\section{Introduction}

Polymers are the important part of our daily use products and polymeric waste disposal is one of the major issues for our society. Many researchers have worked on polymer recycling using various techniques [1-3]. Based on their re-mouldability behavior, polymers are classified as thermoplastic and thermosetting polymers. Recycling of thermoplastic polymers is somewhat easier but thermosetting can't be re-moulded which makes recycling of thermosetting polymers arduous and a challenging. In this competitive era reduction of waste by recycling at lower costs is major concern for researchers [1]. Composting and land filling is widely used for waste disposal but to meet the current needs of the society waste generation is increased so recycling of waste is the need of the hour. The MF is a thermosetting material which cannot be easily recycled and re-moulded and is used in many daily use products (tableware, clock cases, utensil handles, lamination applications etc.) generating huge quantity of waste [2]. Reinforcements in polymers results in enhancing the recycled polymer properties and upgrade their suitability for utilizing in manufacturing applications. Using recycled polymers helps in reducing the manufacturing cost of FDM printed functional prototypes [3]. ABS is broadly used thermoplastic material in various automobile applications and different end use and household products. Amount of waste generated for the specific material is comparatively higher when that material has more utilization in daily life products. Many of the researchers have worked on recycling of waste ABS $[4,5]$ using different recycling techniques. Few researchers have reported recycling of thermosetting polymers and by using it as reinforcement for preparation of feedstock filament for FDM. The literature review reveals that the addition of thermosetting polymer makes the composite hard and brittle. Some researchers have worked on waste MF generated from the manufacturing of decorative paper and their use gives better mechanical properties and enhanced dimensional stability [6]. Powdered MF waste can be used as particleboard binder which gives satisfactory water resistance to particleboard [7]. In biomedical applications, twin screw extrusion (TSE) of almond skin powder reinforced polylactic acid was performed for preparing filament of high mechanical performance which has been used for scaffold printing on FDM [8]. Some studies have been reported on printing of green parts using a composite made by blending tyre waste and polypropylene in 60:40 proportions $[9,10]$. A study has been reported on

*Correspondingauthor:brar.gurinder@gmail.com 
mechanical behavior and surface analysis of $3 \mathrm{D}$ printed parts of ABS reinforced with bakelite (thermosetting polymer) along with ceramic particles $\left(\mathrm{Al}_{2} \mathrm{O}_{3}\right.$ and $\left.\mathrm{SiC}\right)$ by using scanning electron microscopy (SEM) and Xray spectroscopy [11]. It has been ascertained that $3 \mathrm{D}$ printing is a cost effective technology, even then it can't completely replace the injection moulding for bigger lot size but proffer cost effective options for customized production runs under 200 units [12]. Significant improvement was seen in tensile strength and electrical conductivity of multiwall carbon nano-tubes reinforced ABS 3D printing filament of $1.7 \mathrm{~mm}$ diameter made by using twin screw micro-compounding extruder with further processing in single screw extruder [13]. In another study, it has been found that development of feedstock filament using double particle size low density polyethylene with reinforced $\mathrm{Al}_{2} \mathrm{O}_{3}$ given enhanced mechanical properties of the filament (increased hardness and better dimensional stability) [14]. A feedstock filament of ferromagnetic nature have been developed using Fe-Nylon 6 composite material having better mechanical, thermal and rheological properties as compared to commercial ABS-P430 feedstock material [15]. In an another study it has been reported that poly lactic acid filament with reinforced wood particles show better tensile strength up to $10 \%$ of wood content with no change in glass transition temperature of filament [16, 17]. The environmental impact of $3 \mathrm{D}$ printing is also being noticed by some researchers based upon factors such as waste management, pollution control and resource consumption and has been reported that $3 \mathrm{D}$ printing is more material efficient [18], consumes more energy because of lower productivity and uses fewer harmful chemicals in comparison with subtractive manufacturing and hence is environmental friendly and also capable of making complex and efficient product design [19]. The biocompatible feedstock filament was prepared using $96 \%$ polymer matrix (70\% polyvinyl chloride $30 \%$ polypropylene) and $4 \%$ hydroxyapatite with TSE and the filament was used for preparation of biocompatible dentures [20]. The sustainability of recycled polymers ABS and PA6 blended with agricultural waste i.e. banana fibre was tested by making feedstock filament and was tested for mechanical properties and results claimed the enhanced mechanical properties of the filament [21]. The commercial recycling of thermoplastics for sustainable manufacturing is quite common as these polymers can be reshaped on heating/ cooling, but recycling of thermosetting polymers is still one of the major challenges. For thermoplastic polymers, recycling can be performed by adopting different routes like: mechanical (primary and secondary), chemical (tertiary) and thermal utilization (quaternary) but these means for polymer recycling do not work well with thermosetting polymers because of extensive cross linking of polymeric chains (observed on curing thermosetting polymers resulting in irreversibly hardened, infusible and insoluble polymer network) [12-17]. In the present research work, effort has been made for recycling of thermosetting polymer; MF as reinforcement in ABS thermoplastic as secondary way of recycling by varying proportion of MF for sustainable manufacturing. The polymer matrix composite comprising of ABS as matrix has been prepared by reinforcement of MF with TSE followed by $3 \mathrm{D}$ printing on open source FDM setup.

\section{Materials and methods}

For the present study, virgin ABS was procured from Batra polymers, Ludhiana (India) and waste MF powder generated at the time of kitchenware manufacturing was procured from Shiva Industries, Ludhiana (India). Both the materials were preheated in hot air oven for $1 \mathrm{hr}$ at a temperature of $50^{\circ} \mathrm{C}$ to remove moisture content before the experimentation. Various proportions of ABS-MF were tested for their flow characteristics in melting temperature range (as per ASTM D1238 standards) using melt flow indexer. The wires and pins were prepared using different proportions of ABS-MF. After testing the rheological properties of the various compositions, feedstock filaments with favorable results of MFI were prepared for different ABS-MF ratios using TSE with input parameters: Torque $=0.3 \mathrm{Nm}$, Load $=$ $12.5 \mathrm{~kg}$, Temperature $=230^{\circ} \mathrm{C}$. These samples were further tested for their thermal behavior on DSC, tensile strength using universal tensile testing setup (UTM) and wear behavior by using pin on disc apparatus. The worn out cross-sections of the pins were observed by using Tool maker's microscope and inverted metallurgical microscope to check the morphology and porosity of the cross-sections. Initially virgin ABS and powdered MF were blended in different \%age compositions/ proportions (by wt.). The coconut oil was used as binder in this study. MF was used in various compositions/ proportions up to $27.5 \%$ with ABS matrix and MFI of the blend was observed at $230^{\circ} \mathrm{C}$ for different compositions (by following ASTM D1238 standards) using weight of $3.8 \mathrm{~kg}$ (Fig. 1). After checking the rheological properties of the various samples, depending on the flowability of the composite matrix it was found out that maximum of $25 \%$ of MF can be blended in ABS-MF composite for making FDM feedstock filament. Using the relation between MFI, Viscosity and density of material [22], the viscosity of the samples was calculated (Table 1).

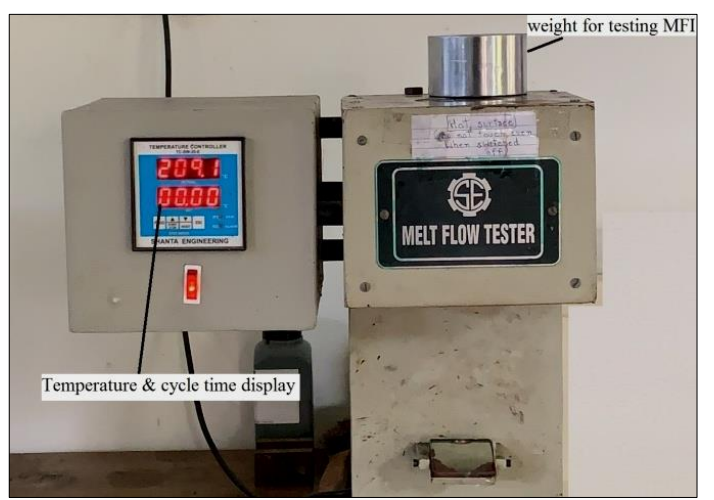

Fig. 1. Melt flow indexer. 
Table 1.MFI of various ABS-MF compositions.

\begin{tabular}{|l|l|l|l|l|}
\hline $\begin{array}{l}\text { Sample } \\
\text { no. }\end{array}$ & $\begin{array}{l}\text { \%age of } \\
\text { ABS by } \\
\text { weight }\end{array}$ & $\begin{array}{l}\text { \%age } \\
\text { of MF }\end{array}$ & $\begin{array}{l}\text { MFI (in } \\
\text { gm/10 } \\
\text { min) }\end{array}$ & $\begin{array}{l}\text { Viscosity } \\
\text { (Pa-s) }\end{array}$ \\
\hline 1 & 100 & 0 & 12.252 & 1445.53 \\
\hline 2 & 97.5 & 2.5 & 12.104 & 1496.46 \\
\hline 3 & 95 & 5 & 11.997 & 1561.28 \\
\hline 4 & 92.5 & 7.5 & 11.784 & 1627.90 \\
\hline 5 & 90 & 10 & 11.359 & 1715.09 \\
\hline 6 & 87.5 & 12.5 & 10.648 & 1873.66 \\
\hline 7 & 85 & 15 & 9.411 & 2022.31 \\
\hline 8 & 82.5 & 17.5 & 8.614 & 2598.53 \\
\hline 9 & 80 & 20 & 7.421 & 2980.35 \\
\hline 10 & 77.5 & 22.5 & 6.612 & 3215.87 \\
\hline 11 & 75 & 25 & 4.871 & 4125.59 \\
\hline & & & $\begin{array}{l}\text { Material } \\
\text { got stuck } \\
\text { inside } \\
\text { barrel }\end{array}$ & No value \\
\hline 12 & 72.5 & 27.5 & & \\
\hline
\end{tabular}

Based upon Table 1, feedstock filaments of different compositions/ proportions with $\Phi 2 \mathrm{~mm}$ were tested for their tensile strength using UTM (as per ASTM D638 type IV standards). The results of tensile testing are given in Table 2 and corresponding stress strain curve is shown in Fig. 2.

Table 2. Results of tensile test performed on UTM

\begin{tabular}{|c|c|c|c|c|c|c|}
\hline $\begin{array}{l}\text { Sa } \\
\text { mpl } \\
\text { e } \\
\text { no. }\end{array}$ & $\begin{array}{l}\text { Peak } \\
\text { Loa } \\
(\mathrm{N})\end{array}$ & $\begin{array}{l}\text { Peak } \\
\text { Elong } \\
\text { ation } \\
(\mathrm{mm})\end{array}$ & $\begin{array}{l}\text { Break } \\
\text { Load } \\
(\mathrm{N})\end{array}$ & $\begin{array}{l}\text { Break } \\
\text { Elong } \\
\text { ation } \\
(\mathrm{mm})\end{array}$ & $\begin{array}{l}\text { Strength } \\
\text { at Peak } \\
\left(\mathrm{N} / \mathrm{mm}^{2}\right)\end{array}$ & $\begin{array}{l}\text { Strength } \\
\text { at Break } \\
\left(\mathrm{N} / \mathrm{mm}^{2}\right)\end{array}$ \\
\hline 1 & 81.3 & 4.37 & 73.17 & 5.89 & 25.89 & 23.3 \\
\hline 2 & 74 & 3.42 & 66.6 & 3.8 & 23.57 & 21.21 \\
\hline 3 & 76 & 2.47 & 68.4 & 2.85 & 24.2 & 21.78 \\
\hline 4 & 77.4 & 2.66 & 69.66 & 2.92 & 24.65 & 22.18 \\
\hline 5 & 89.7 & 2.28 & 80.73 & 2.42 & 28.57 & 25.71 \\
\hline 6 & 91.6 & 2.28 & 82.44 & 2.39 & 29.17 & 26.25 \\
\hline 7 & 72.5 & 1.9 & 65.25 & 2.07 & 23.09 & 20.78 \\
\hline 8 & 67.1 & 1.71 & 60.39 & 1.79 & 21.37 & 19.23 \\
\hline 9 & 59.3 & 1.33 & 53.37 & 1.35 & 18.89 & 17 \\
\hline 10 & 49 & 1.52 & 44.1 & 1.52 & 15.61 & 14.04 \\
\hline 11 & 46 & 1.33 & 41.4 & 1.33 & 14.65 & 13.18 \\
\hline
\end{tabular}

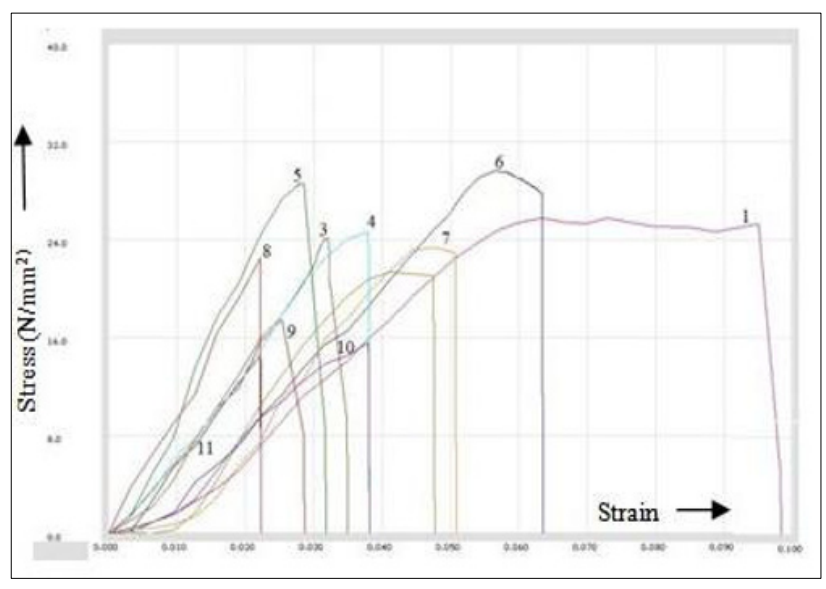

Fig. 2. Stress-strain curves of various samples (as per Table 2)

To determine the wear behavior of various samples wear test was performed on pin on disc apparatus as per ASTM G99-17 (based upon Table 1). In this experimentation, an emery paper (1000 grade) was pasted on the disc and pin was fixed in the pin holder of the testing apparatus and the test was performed using $0.5 \mathrm{~kg}$ weight on pin with disc rotating at $72 \mathrm{rpm}$ for the cycle time of 2 min for each sample. All the samples were weighed before and after the test and composite matrix wear was expressed in terms of weight loss of the pins (Table 3). Based upon Table 3, porosity analysis of prepared samples were made as per ASTM B276 05(2015) and it was observed that porosity of the samples goes on decreasing with increase in MF content from $0 \%$ to $12.5 \%$ and after this porosity trend was reversed (Fig.3).

Table 3. Pin on Disc test results to determine wear of samples

\begin{tabular}{|l|l|l|l|}
\hline $\begin{array}{l}\text { Sample } \\
\text { no. }\end{array}$ & $\begin{array}{l}\text { Initial } \\
\text { Weight (in } \\
\text { mg) }\end{array}$ & $\begin{array}{l}\text { Final } \\
\text { Weight (in } \\
\text { mg) }\end{array}$ & $\begin{array}{l}\text { Weight } \\
\text { loss (in } \\
\text { mg) }\end{array}$ \\
\hline 1 & 2.67 & 2.651 & 0.019 \\
\hline 2 & 2.897 & 2.879 & 0.018 \\
\hline 3 & 3.238 & 3.222 & 0.016 \\
\hline 4 & 2.98 & 2.965 & 0.015 \\
\hline 5 & 2.688 & 2.676 & 0.012 \\
\hline 6 & 2.491 & 2.479 & 0.012 \\
\hline 7 & 2.249 & 2.236 & 0.013 \\
\hline 8 & 3.279 & 3.262 & 0.017 \\
\hline 9 & 2.251 & 2.233 & 0.018 \\
\hline 10 & 2.54 & 2.519 & 0.021 \\
\hline 11 & 2.521 & 2.498 & 0.023 \\
\hline
\end{tabular}




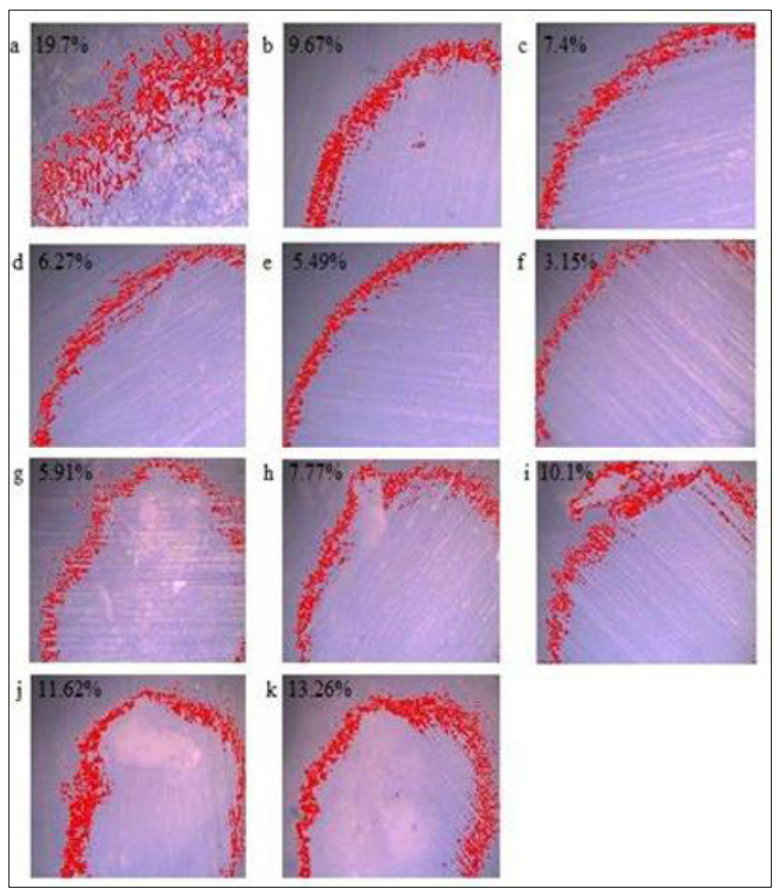

Fig. 3. Observations (at $\times 100$ ) (a) sample 1; (b) sample 2; (c) sample 3; (d) sample 4; (e) sample 5; (f) sample 6; (g) sample 7; (h) sample 8; (i) sample 9; (j) sample 10; (k) sample 11

\section{Results and Discussions}

Based upon Table 2, 3 and Fig. 3 the sample with best wear and tensile properties were subjected to thermal analysis by heating it to $230^{\circ} \mathrm{C}$ and cooling it to $30^{\circ} \mathrm{C}$ for continuous three cycles on DSC setup and comparison was made with virgin ABS (Fig. 5). As observed from Fig. 5, heat capacity of the sample with $88.5 \%$ ABS and $12.5 \% \mathrm{MF}$ (sample 6 as per Table 1 ) is better than virgin ABS sample. However in repeated cycles the energy absorbing capacity got reduced for both samples, but the degradation rate for virgin ABS (sample 1) was more. Hence it may be ascertained that sample 6 is more thermally stable.

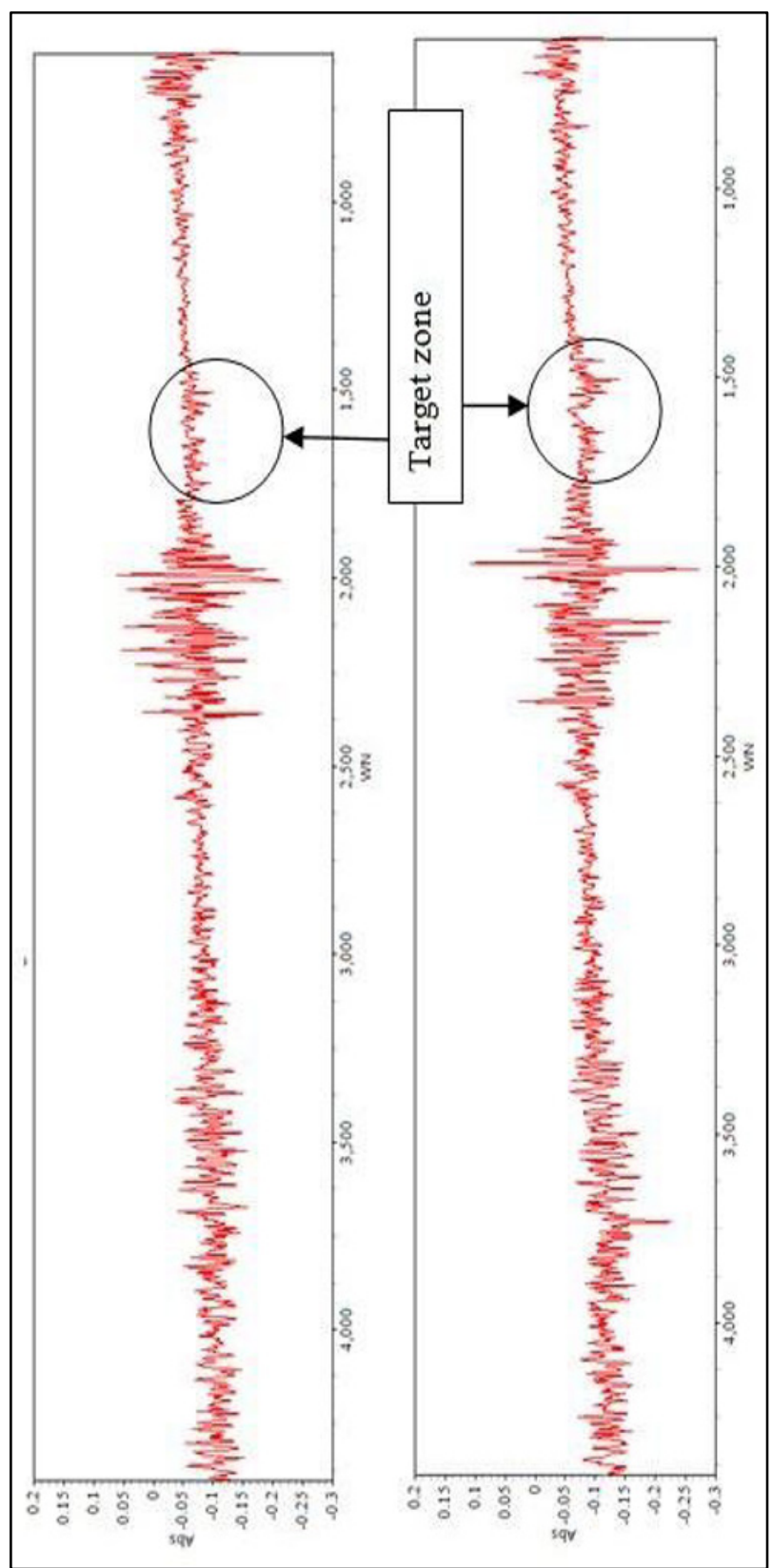

Fig. 4. FTIR for selected samples ( 1 and 6 , as per Table 1 )

Fig. 4 shows FTIR graphs for sample 1 and 6. As observed from Fig. 4, improvement in bond strength has been observed for sample 6. Further at high wave number (WN) the absorbance (Abs) was observed below zero. Hence the proposed composite may be used in sensor applications (especially for intercepting low frequency signals). 


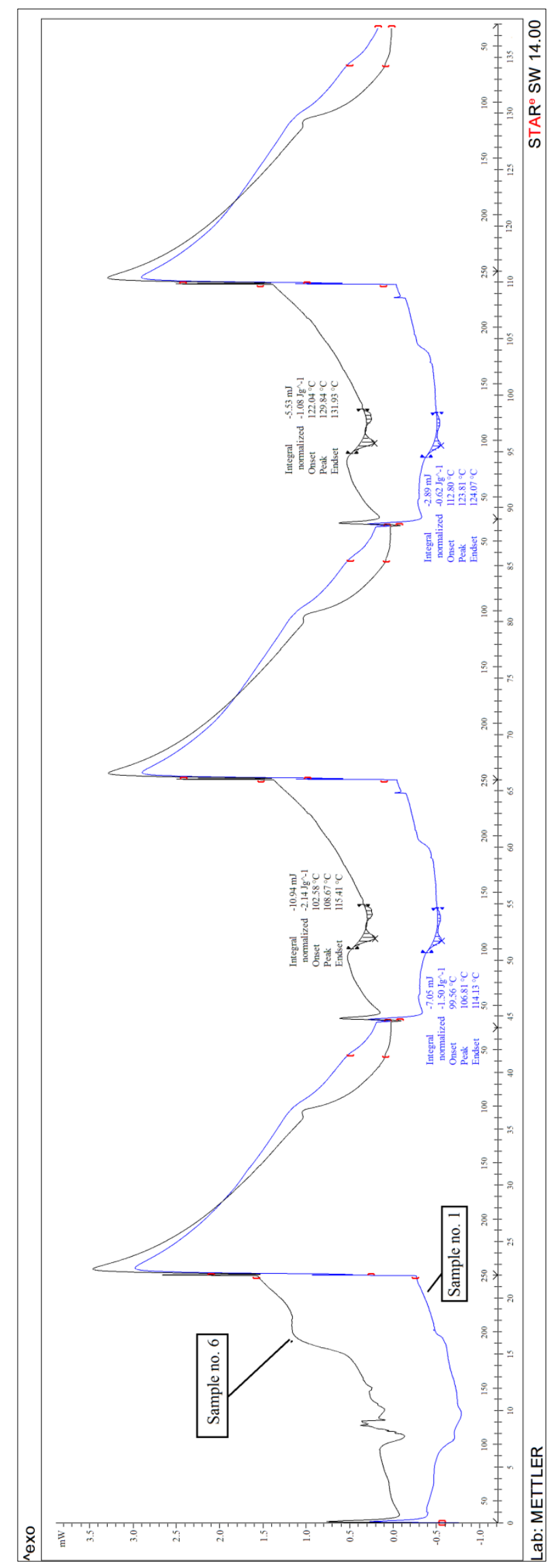

Fig. 5. Fig. 4 DSC for selected samples (as per Table 1)

Further while testing the rheology of various samples of ABS-MF composite matrix, decreasing trend of MFI and increasing trend of viscosity has been observed with increase in the MF proportion. As observed from Table 1 , it has been ascertained that as proportion of MF in matrix reaches $27.5 \%$, material got stuck in the barrel of melt flow indexer. Therefore, no further experimentations were performed for this particular sample as this composition can't be used for manufacturing feedstock filament for FDM. Further based upon Table 1, Fig. 6 shows the trends of MFI and viscosity with increase in proportion of MF up to $25 \%$ of $\mathrm{MF}$ in composite matrix. Based upon Fig. 6, an interesting observation has been made that the intersecting point of MFI and viscosity curves may give directional indicator in a way that after this point the properties of selected proportion of MF in ABS matrix is going to be seriously compromised. As observed from Fig. 6 the $17.5 \%$ proportion of MF in ABS seems to be the intersection point of MFI and viscosity curves and while comparing the tensile and wear properties (Table 2,3 ) it has been ascertained that these properties were compromised after the intersection point. Hence the user may use this intersection point as a limiting value for fine tuning the reinforcement proportion in selected matrix material. Further less adhesion of ABS and MF with higher proportion of MF may be the reason for decrease in MFI. Tensile test results of feedstock filaments with different compositions as per Table 2 were plotted as stress-strain curves (Fig. 2). As observed from Fig. 6 the increasing trend for strength up to $12.5 \%$ proportion of MF was noticed and after that the trend reverses. For virgin ABS, high porosity was noticed in the extruded wire (Fig. 3), and when MF was blended with ABS it lowers the porosity and hence increases the strength of the feedstock filament but as the proportion of MF was further increased above $12.5 \%$, the improper adhesion of MF powder with ABS may have reduced the strength of the feedstock filament. It was also observed that addition of MF in the ABS makes the matrix brittle as results shows the decreasing values for peak elongation with more MF content in sample (Table 2). The samples with MF more than $15 \%$ become more brittle and feedstock filament handling is more difficult as it cannot be rolled because of high brittleness. Therefore, from the results of tensile test it was ascertained that $12.5 \% \mathrm{MF}$ is suitable proportion for feedstock filament fabrication. Based upon Table 3, it has been observed that the wear resistance of composite matrix goes on increasing up to the $12.5 \% \mathrm{MF}$. This may be because the porosity in the virgin ABS pins was compensated by MF reinforcement and the better adhesion of ABS and MF improved the wear resistance but on further increase in MF proportion adhesiveness of MF and ABS in molten state decreases and thus wear of the pins with MF concentration above $12.5 \%$ was more. Morphology of the cross-section of the pins used for wear testing is shown in Fig. 7. As observed from Fig. 7, wear and abrasions lines were prominent up to $12.5 \%$ proportion of $\mathrm{MF}$ in $\mathrm{ABS}$ matrix and above $12.5 \%$ proportion more voids/pores were noticed in the pin cross-section, which may be responsible for poor wear characteristics. 


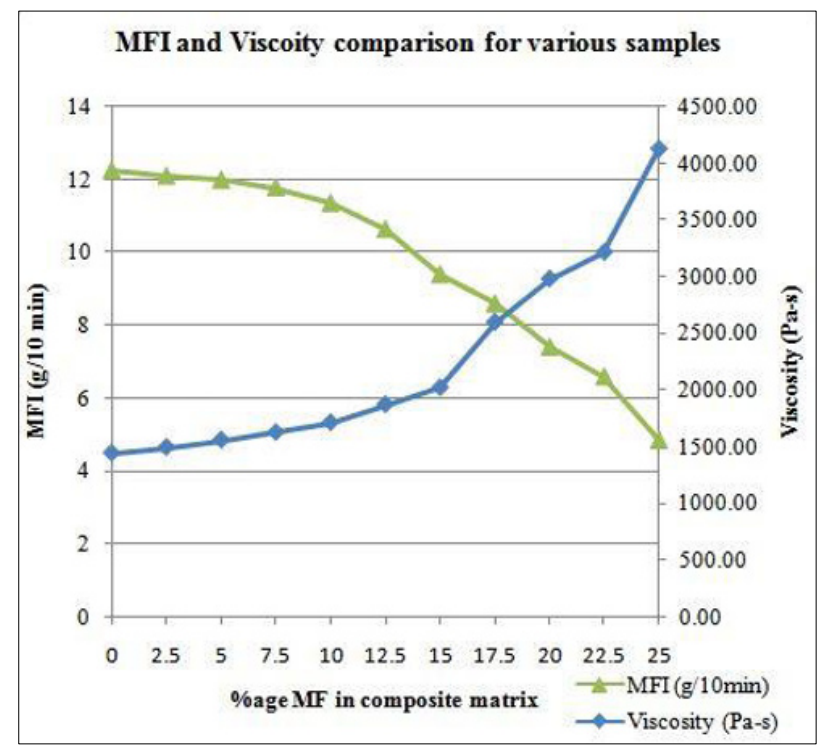

Fig. 6. MFI and viscosity relation for various samples (as per Table 1)

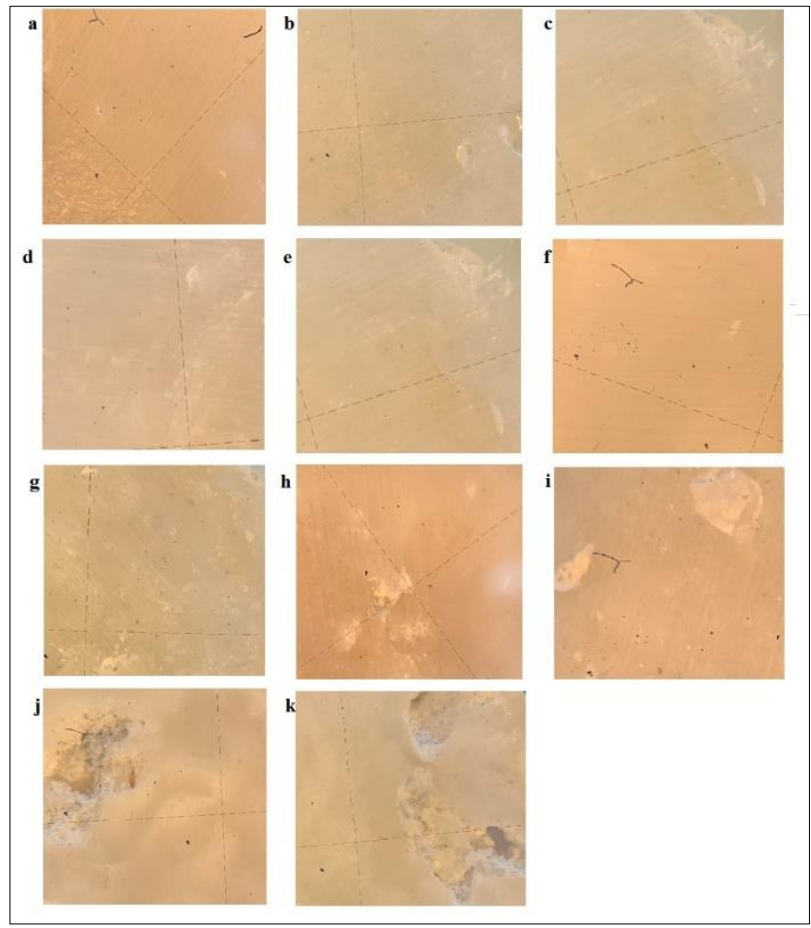

Fig. 7. Morphology of samples after wear testing (at $\times 30)$ on Tool maker's microscope (a) sample 1; (b) sample 2; (c) sample 3; (d) sample 4; (e) sample 5; (f) sample 6; (g) sample 7; (h) sample 8; (i) sample 9; (j) sample 10; (k) sample 11(as per Table 3)

\section{Conclusions}

In this study experimental investigations were performed to understand ABS-MF composite matrix is suitable for sustainable manufacturing. Following are the conclusions from this study:

$\rightarrow$ The results of study suggest that $12.5 \%$ of MF as reinforcement in ABS provides the better matrix proportion to operate on FDM based 3D printer as a feedstock filament material from rheological, porosity and morphology view point. It has been ascertained that for selected MF proportion MFI of $10.648 \mathrm{~g} / 10 \mathrm{~min}$ and viscosity of $1873.66 \mathrm{~Pa} . \mathrm{s}$ was achieved, which is sufficient for commercial 3D printing of moderate and thin sections.

$\rightarrow$ For selected ABS matrix with 12.5\% $\mathrm{MF}$ proportion has resulted into better tensile strength to feedstock filament with moderate ductility. However while comparing the stress- strain curve for sample 1 (virgin ABS) and sample 6 (as per Table 1) the area under the curve was noticed to be reduced, which indicates reduction in modulus of toughness. In other words the MF reinforced sample resulted into relatively poor impact properties.

$\rightarrow$ Overall the MF reinforcements resulted into better wear resistance to abrasive materials as compared to virgin ABS. Also the bonding capabilities and thermal stability was observed to be improved.

The authors are thankful to NITTTR Chandigarh and GNDEC Ludhiana for lab facilities.

\section{References}

1. M. Al-Madeed, N.K. Madi, R. Kahraman, A. Hodzic, N.G. Ozerkan, Qatar. J Polym Environ, 20, 186 (2012)

2. R. Thomas, P. Vijayan, S. Thomas, Recents Developments in Polymer Recycling, 121 (2011).

3. D. Lee, Y. Lee, K. Lee, Y. Ko, N. Kim, Journal Manufacturing Science and Engineering 141, 1 (2018)

4. R. Singh, H. Singh, I. Farina, F. Colangelo, F. Fraternali, Composites Part B:Engg. 156, 259 (2019)

5. R. Singh, G.S. Sandhu, R. Penna, I. Farina, Materials 10, 881 (2017)

6. R. Singh, I. Singh, R. Kumar, G.S. Brar, Journal of Thermoplastic Composite Materials 34, 1 (2019)

7. M.G. Dube, G.L. Batch, J.H. Vogel, C.W. Macosko, Polymer Composites 16, 378 (2004)

8. R. Singh, R. Kumar, Pawanpreet, M. Singh, J. Singh, Journal of Thermoplastic Composite Materials, 1 (2019)

9. M. Despeisse, S. Ford, APMS 2015, Part II, 29 (2015)

10. J. Domingues, T. Marques, A. Mateus, P. Carreira, C. Malça, Procedia Manufacturing 12, 242 (2017)

11. R. Singh, I. Singh, R. Kumar, Proc IMechE Part C, J. Mechanical Engg. Science 0, 1 (2019).

12. M. Franchetti, C. Kress, Int J. Adv. Manufacturing Technology 88, 2573 (2017)

13. H.K. Sezer, O. Eren, Journal of Manufacturing Processes 37, 339 (2019)

14. P. Bedi, R. Singh, I.P.S. Ahuja, Virtual and Physical Prototyping 13, 1 (2018)

15. H. K. Garg, R. Singh, Materials Science Forum $\mathbf{8 0 8 , 1 0 3 ~ ( 2 0 1 5 ) ~}$ 
16. M. Kariz, M. Sernek, M. Obućina, M.K. Kuzman, Materials Today Communications 14, 135 (2018)

17. X. Li, Z. Ni1, S. Bai, B. Lou, Preparation and mechanical properties of Fiber reinforced PLA for $3 D$ printing materials in IOP Conf. Ser.: Mater. Sci. Engg. 322, 022012 (2018)

18. Ch. Achillasa, D. Aidonis, E. Iakovouc, M. Thymianidisa, D. Tzetzis, Journal of Manufacturing Systems 37, 328 (2015)

19. T. Penga, K. Kellens, R. Tang, C. Chenc, G. Chen,. Additive Manufacturing 21, 694 (2018)

20. R. Singh, N. Ranjan, Journal of Thermoplastic Composite Materials 31, 1-15(2017)

21. R. Singh, R. Kumar, N. Ranjan.. J. Inst. Eng. India Ser. C 100, 351 (2019)

22. R. Sharma, R. Singh, A. Batish, Journal of thermoplastic composite materials, 1 (2020) 